\title{
Discussion on the Application of Highway Maintenance Platform Based on GIS + BIM Technology-Taking Gansu Province as an Example
}

\author{
Juming Hao' , Jianbin Zhu' ${ }^{2}$, Tongyang $\mathrm{Li}^{3}$, Ruotong $\mathrm{Li}^{3}$, Yuanqing Wang ${ }^{3}$ \\ ${ }^{1}$ Gansu Highway and Transportation Construction Group Co., Ltd., Lanzhou, China \\ ${ }^{2}$ Shenzhen Expressway Engineering Consulting Co., Ltd., Shenzhen, China \\ ${ }^{3}$ Chang'an University, Xi'an, China \\ Email:1085186485@qq.com
}

How to cite this paper: Hao, J.M., Zhu, J.B., Li, T.Y., Li, R.T. and Wang, Y.Q. (2021) Discussion on the Application of Highway Maintenance Platform Based on GIS + BIM Technology-Taking Gansu Province as an Example. World Journal of Engineering and Technology, 9, 765-781. https://doi.org/10.4236/wjet.2021.94053

Received: August 23, 2021

Accepted: October 22, 2021

Published: October 25, 2021

\begin{abstract}
Gansu Province is a large province in Western China, and its geographical location and economic status are very important. With the state's attention to the western development, the economy of the western region represented by Gansu Province has developed rapidly, and the construction of roads and other infrastructure has also been developed. Taking Gansu Province as an example, this paper studies and discusses the application of highway maintenance platform based on GIS + BIM Technology. Firstly, this paper expounds the advantages of GIS + BIM Technology in highway construction and maintenance, and analyzes the development status of GIS + BIM Technology; Secondly, it expounds how to solve the problem of highway maintenance from the aspects of GIS + BIM system and its advantages and difficulties in highway maintenance, and briefly explains the difficulties existing in highway maintenance in Gansu Province. Then, starting from the path of GIS + BIM Technology to solve highway maintenance in Gansu Province, this paper analyzes the expected effect of GIS + BIM Technology in highway maintenance in Gansu Province.
\end{abstract}

\section{Keywords}

GIS + BIM Technology, Highway, Research on Maintenance Platform, Gansu Province

\section{Advantages of GIS + BIM Technology in Highway Maintenance}

Since the $13^{\text {th }}$ five year plan, under the leadership of Gansu provincial Party 
committee and Gansu provincial government, Gansu highway construction has made significant progress. But at the same time, the design grade and technical standard of highway are generally low, and the planning and construction often cannot keep up with the demand of traffic growth; secondly, roads are repaired first and then maintained. Untimely maintenance leads to high highway damage rate, insufficient construction funds and maintenance management funds, and it is difficult to timely and reasonably ensure highway safety; In addition, there are many hidden dangers of road accidents, such as weak safety awareness of traffic participants, illegal driving, imperfect road traffic safety facilities, imperfect road protection works and other prominent problems, resulting in difficulties in road maintenance and management. Especially under the background of streamlining road management personnel, the maintenance efficiency of roads can be continuously improved through better local management [1].

As a tool of engineering digitization, BIM is an engineering construction information system proposed to solve engineering information-based. The attribute information in BIM model can be accurate to component level, and has the advantages of visualization, large amount of information and good coordination. BIM Technology has great technical advantages for high-way projects with wide distribution, medium and short circuit sections [2]. After decades of development, the research and application of GLS technology is gradually mature, which can effectively process a large number of large-scale terrain data. Therefore, combining the advantages of BIM and GIS can better provide rich, comprehensive and high-quality visual information for highway maintenance projects [3].

\section{Current Development of GIS + BIM Technology}

As for the development of highway information technology, the relevant research in the United States, Canada and other countries is earlier. They designed a road maintenance management system, called pavement management system, which was only aimed at road design and construction at the beginning, and then comprehensively promoted it. It is the prototype of North American road information integrated management system. At present, foreign developed countries have realized comprehensive monitoring of traffic trunk roads and bridges. An intelligent information system capable of all-weather real-time monitoring shall be established to fully grasp the conditions of all sections within the jurisdiction, report highway maintenance information at the first time, and carry out maintenance management according to the scale of maintenance projects and the number of resources. The MIS also contains dynamic information to view the latest vehicle driving information in each road section.

At the end of the $20^{\text {th }}$ century, the measurement technology using tilt photography gradually developed overseas. In the field of photogrammetry, scientific and technological workers have used tilt photography technology to explore tilt photography system. The traditional vertical photography technology can only obtain the vertical image data, but the tilt photogrammetry method can also ob- 
tain the tilt image when obtaining the images from different angles. After a certain processing process, the real three-dimensional model suitable for human vision can be displayed. Tilt photogrammetry technology started late in China, but the research on this technology abroad is relatively early [4]. At the beginning of 2010, tilt photography technology began to face China. Build Data Technology Co., Ltd. in Beijing used tilt photography technology for the first time, which also marks the beginning of the era of aerial tilt Photogrammetry in China.

Laser point cloud technology based on three-dimensional laser scanning technology first appeared in the 1960s. At that time, the price was relatively high and the image definition was not high, so it was not widely used. Later, due to the progress of industry and the rapid progress in the field of electronics and laser, some developed countries have begun to enter the category of 3D laser scanning. In the 1990s, high-precision 3D point clouds have been quickly obtained by 3D laser scanning technology and used for data processing and conversion. In 2010, the second generation laser scanner applied on the ground was developed in the cartographic Laboratory of Ohio State University [5]. The University of Calgary in Canada has also developed a laser scanning system VISAT that can be used in the field of highway measurement.

At present, China's highway information management still stays in the provincial trunk highway maintenance management. In terms of maintenance management mode, most domestic roads above the provincial level have fully implemented information management, and realized all-weather and all-time monitoring of roads through modern management means.

\section{BIM + GIS System and Its Advantages and Difficulties in Highway Maintenance}

\subsection{Introduction to BIM + GIS System Platform Technology}

The GIS + BIM application sub platform realizes the deep integration of GIS + BIM through data integration, system integration or application integration, gives full play to the respective advantages of BIM and GIS technology, realizes multi-dimensional highway engineering management from macro to micro, integrates engineering quality management, safety management, progress management, measurement management, operation management, maintenance management and other modules, and opens up business data.

\subsection{BIM + GIS System and Its Advantages in Highway Maintenance}

Now, China has introduced BIM Technology into the construction of transportation infrastructure system. The traditional construction system only stays in two-dimensional drawings. BIM, as the carrier of three-dimensional technology, is very popular, which greatly improves the efficiency of traditional project design and operation. In particular, it has been recognized by the industry after proposing to use "intelligent management" in the whole process of the project. The research flow chart is shown in Figure 1. Although BIM Technology is favored 


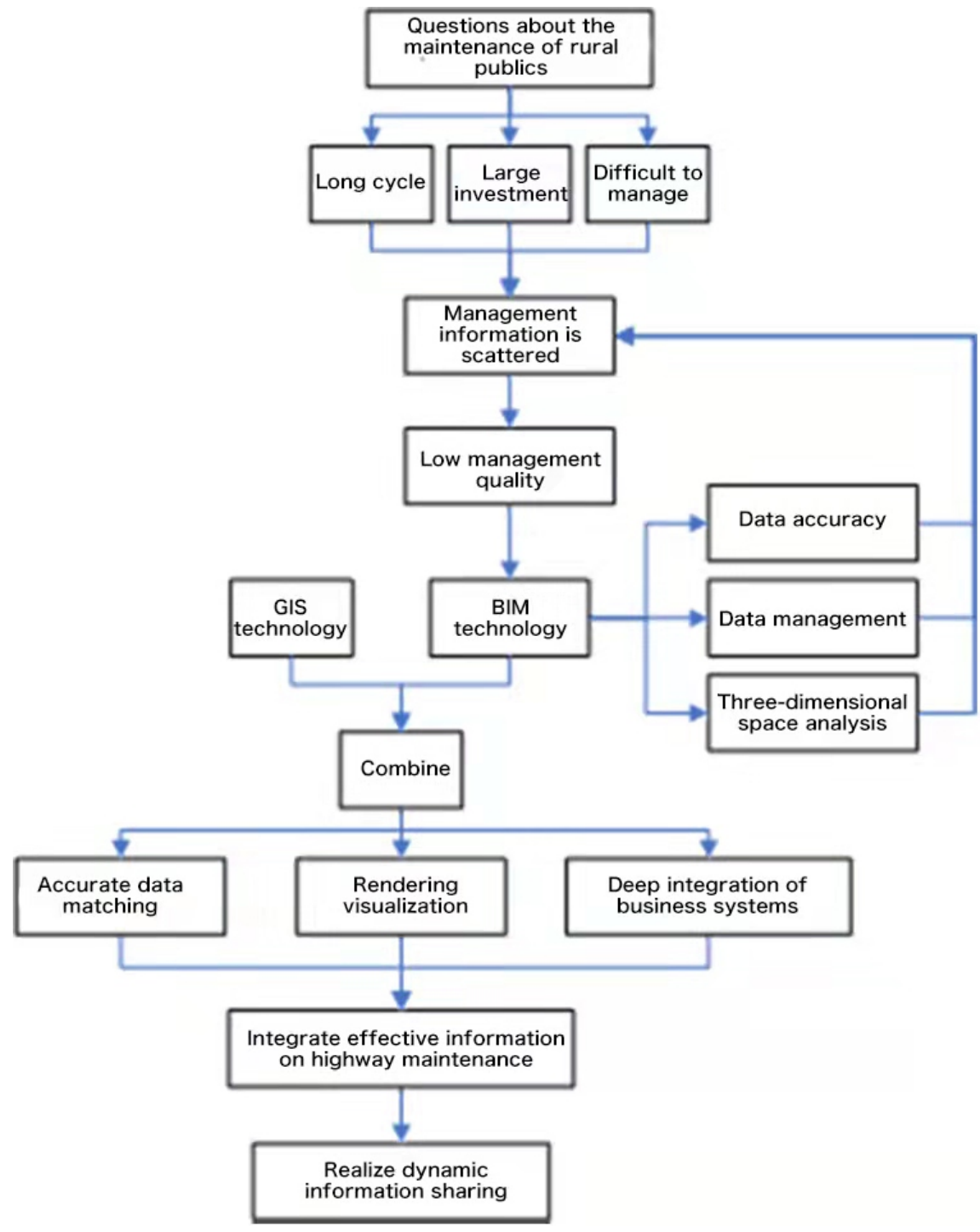

Figure 1. Research and analysis flow chart.

by the construction of transportation facilities, there are still deficiencies in BIM Technology [6]. Firstly, BIM Technology is to manage a single building in the whole cycle in the process of transportation infrastructure construction, but the terrain of the construction site and the surrounding macro scenes cannot be displayed effectively. Secondly, BIM model has no ability to analyze terrain and accurate positioning. It also needs to combine BIM Technology with GIS technology to realize the management of attribute data and spatial data. The traffic infrastructure construction management system combining BIM and GIS improves the efficiency and quality of construction management and realizes onsite intelligence.

Highway maintenance generally has the characteristics of long cycle, large investment and difficult management. Therefore, with the rapid development of infrastructure construction management, "intelligent management" has been paid more and more attention. In the traditional transportation infrastructure 
management system, due to the scattered management information, highway management is very passive, there is no way to perfectly combine the management information with the dynamic information generated in the management process, and the management problems cannot be analyzed and fed back in time, resulting in the stagnation of management work and the reduction of management quality. Intelligent management abandons the traditional management mode, removes the old and single management method, organically combines BIM and GIS technology with highway management, effectively integrates the effective information in highway maintenance, realizes the dynamic sharing of highway maintenance information, improves the efficiency of highway management, and is of great significance to the improvement of the maintenance quality of transportation infrastructure [7].

\subsection{Difficulties in Highway Maintenance in Gansu Province}

By the end of 2020, the highway mileage in Gansu Province will be 2.23 million kilometers, the expressway and first-class highway will exceed 6000 kilometers, the second-class highway and above will be nearly 17,000 kilometers, and the highway mileage will reach 192,000 kilometers (including natural village road). In addition, after the roads planned and constructed in the $14^{\text {th }}$ five year plan are gradually completed, the task of highway maintenance in the province will become more and more important. Naturally, it is necessary to support the huge maintenance market in the province with supporting maintenance system and mechanism, operation mode, organization, mechanical equipment and technological innovation. In particular, the backward management mode and ponding level have brought a significant negative impact on the management and maintenance of highways in Gansu Province. It is mainly reflected in.

1) The complexity of Geology and landform has a great impact on the accuracy of positioning and judgment of highways in the design stage, construction and later maintenance.

2) Most parts of Gansu are above 1000 meters above sea level. Danxia landform is widely distributed in the area, with complex geological conditions and poor engineering geological conditions, which lead to many unforeseen factors in the safety control of highway management and maintenance construction in the later stage.

3) In recent years, the development of highways in Gansu has entered a "golden age", with great pressure on the construction progress, but the existing progress management mode has not adapted to the new era.

\section{Logical and Physical Framework Design of BIM + GIS Applied to Highway Construction, Maintenance and Operation Management}

\subsection{Construction Management Platform}

In view of the current difficulties of highway maintenance in Gansu, it is neces- 
sary to build a management sub platform based on an integrated framework, multi-level and multi system, and use workflow engine, Web Service, GIS, BIM and other information technologies to condense all participants in the construction period of highway engineering project into an organic whole, so as to realize the network collaborative work mode of unified planning, unified standards and coordinated process, It provides a scientific management platform for project management departments at all levels to innovate management mode, improve management mechanism and standardize construction behavior, and also provides data support for operation and maintenance [8].

The platform function carries out overall design and planning according to the business, data and process concerned by different highway project construction management levels, and constructs a platform of SOA architecture mode based on the current mainstream spring cloud one-stop distributed micro service solution [9]. Fully studied the management of five professional dimensions of progress, quality, safety, measurement and environmental protection in the construction process, improved the basic data service of the platform, and realized the whole process and all-round real-time dynamic monitoring according to the pain points of construction quality and safety requirements at all management levels, combined with data access such as video, Internet of things and third-party system [10]. On this basis, the platform adopts the mature Domain Driven Design (DDD) in the industry, takes the basic technical service as the engine, takes the construction basic service as the cornerstone and the construction business service as the core, and realizes the seamless flow of business data at all levels during the construction period through the unified authorization management of the integrated platform.

The logical architecture design of the construction management platform is shown in Figure 2 below.

The construction management information-based sub platform mainly carries out online tracking management in the construction platform according to the real-time data obtained by the construction quality and safety intelligent monitoring system and data acquisition related software and hardware equipment at the level of project management department during the project construction period. The overall architecture of the project can be divided into five logical levels, mainly including display layer, business service layer, basic business service layer, data layer and infrastructure layer.

The physical architecture of the construction management platform is shown in Figure 3 below.

\subsection{Maintenance Management Platform}

The maintenance management sub platform is designed based on the maintenance management requirements during the transportation and nutrition protection period of highway facilities. Based on the integrated framework, it makes full use of the data results in the construction period and operation process, and 
realizes the intelligent management of maintenance early warning and maintenance decision analysis through technical means such as workflow engine, GIS + BIM visualization and big data analysis, so as to improve the maintenance quality and efficiency.

The logical architecture design of the maintenance management platform is shown in the following Figure 4.

The physical architecture design of the maintenance management platform is shown in the following Figure 5.

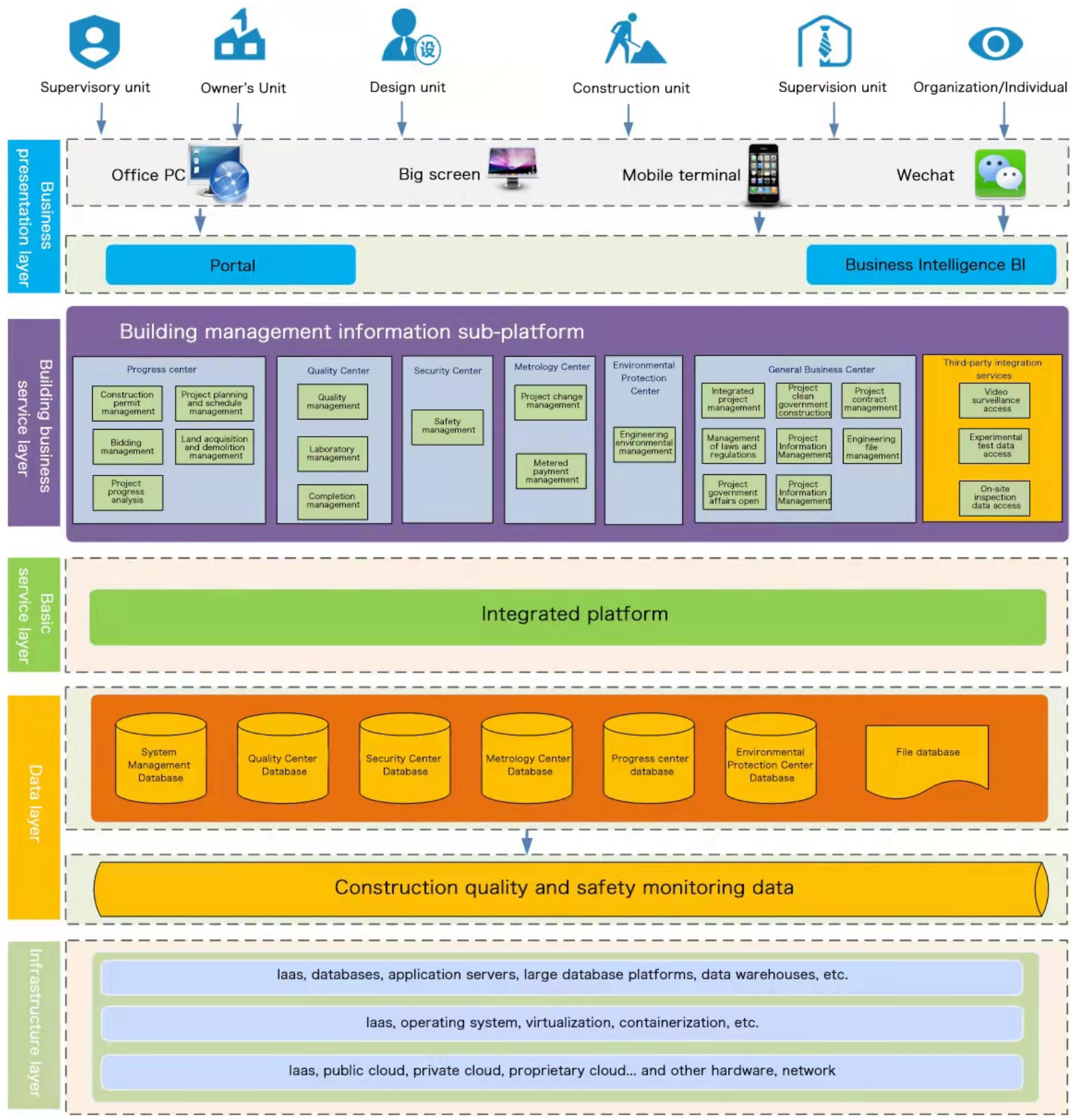

Figure 2. Logical structure design of BIM + GIS applied to highway construction management. 


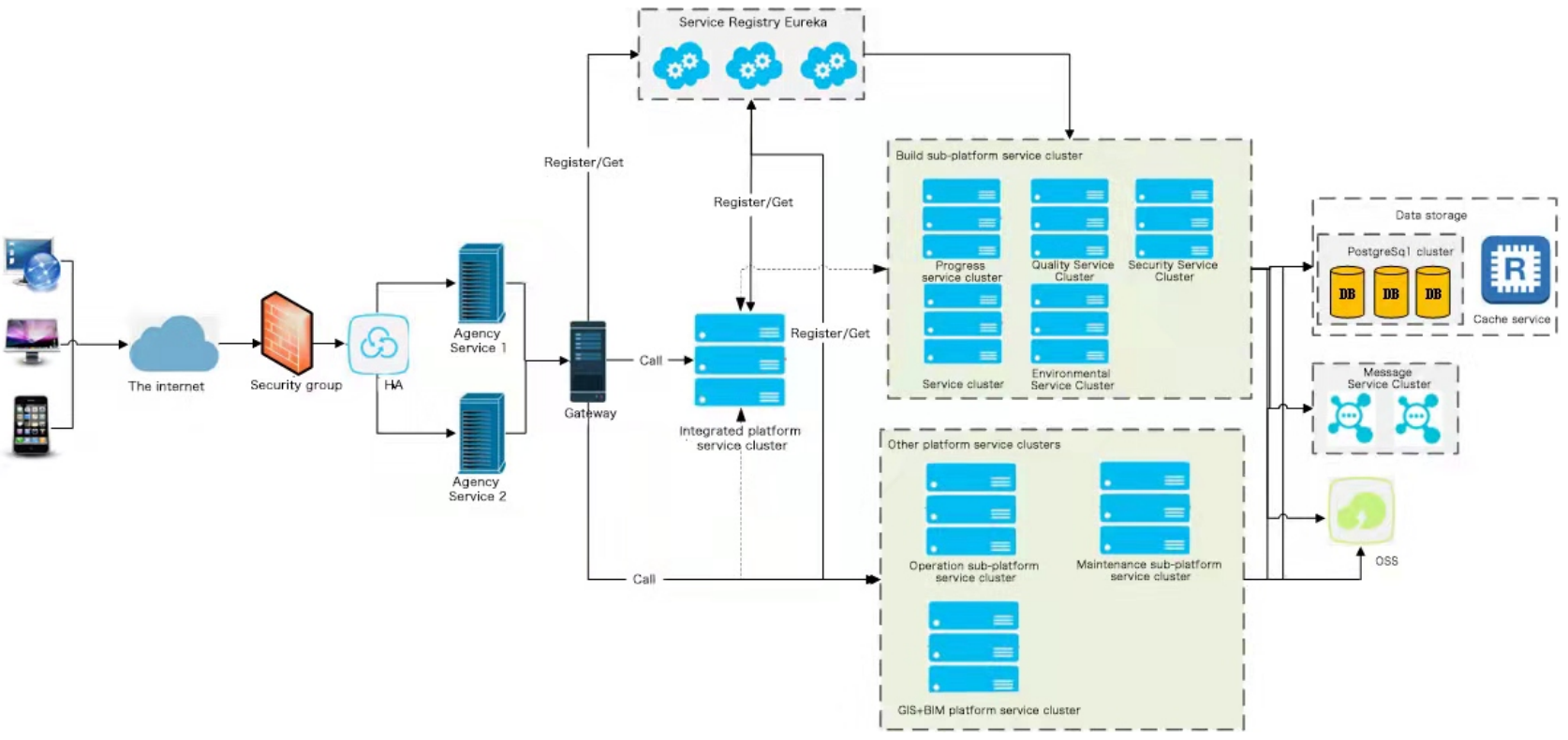

Figure 3. Application of BIM + GIS in physical structure design of highway construction management.

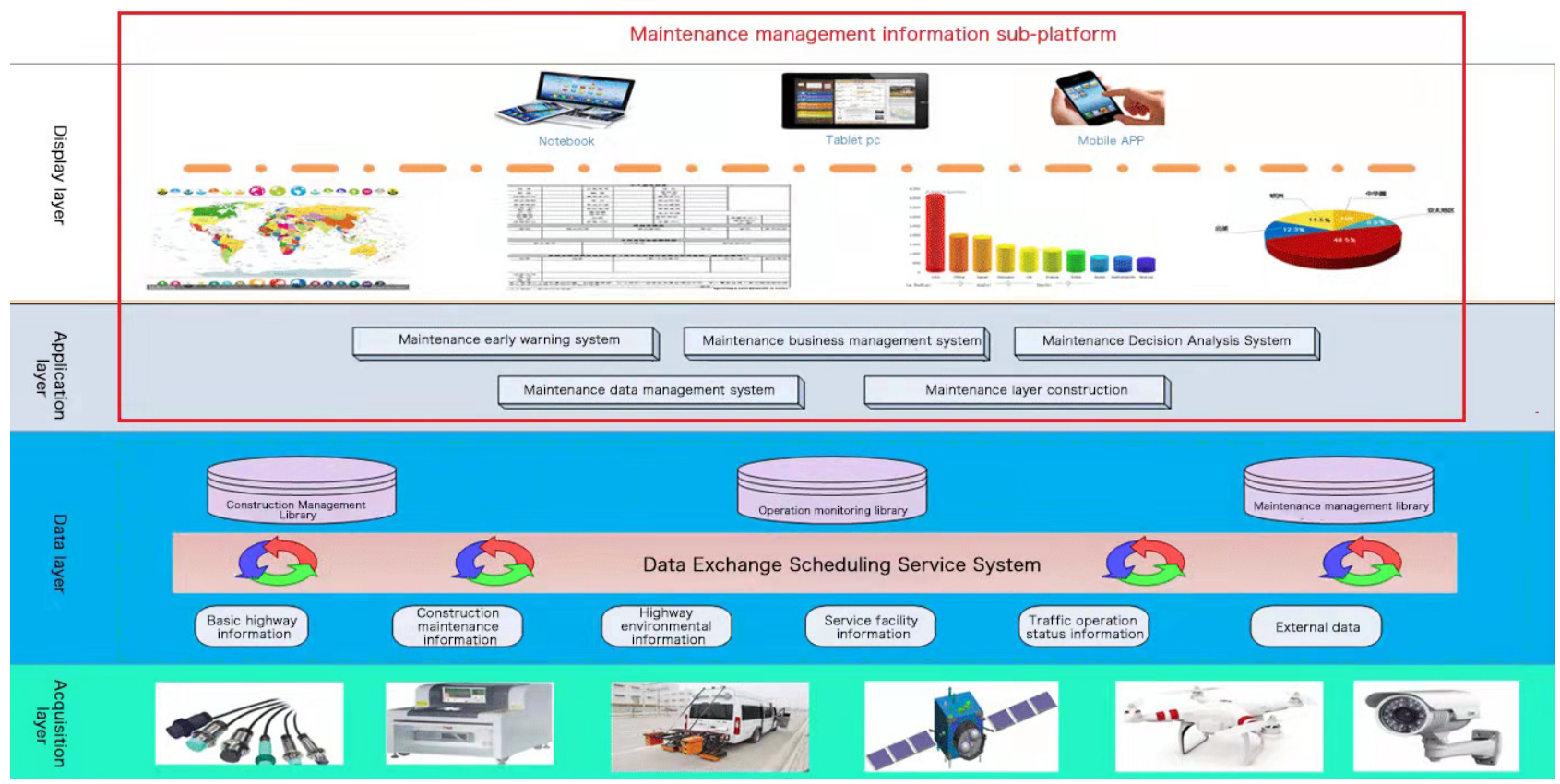

Figure 4. Logical structure design of BIM + GIS applied to highway maintenance management 1) Acquisition layer. The bottom layer is the acquisition layer, which is the basis of the data layer. 2) Data layer. The data layer is the data layer of the whole integrated service platform. 3) Application layer. The application layer consists of maintenance early warning system, maintenance business management system, maintenance decision analysis system, maintenance data management system and maintenance layer construction. 4) Display layer. The application layer systems are used to integrate and analyze the data of the data layer, and the final results are intuitively displayed in forms of tables, pictures, histograms, pie charts, electronic maps and so on through PC and mobile app.

\subsection{Operation Management Platform}

The logical architecture design of the operation management platform is shown in Figure 6 below. 


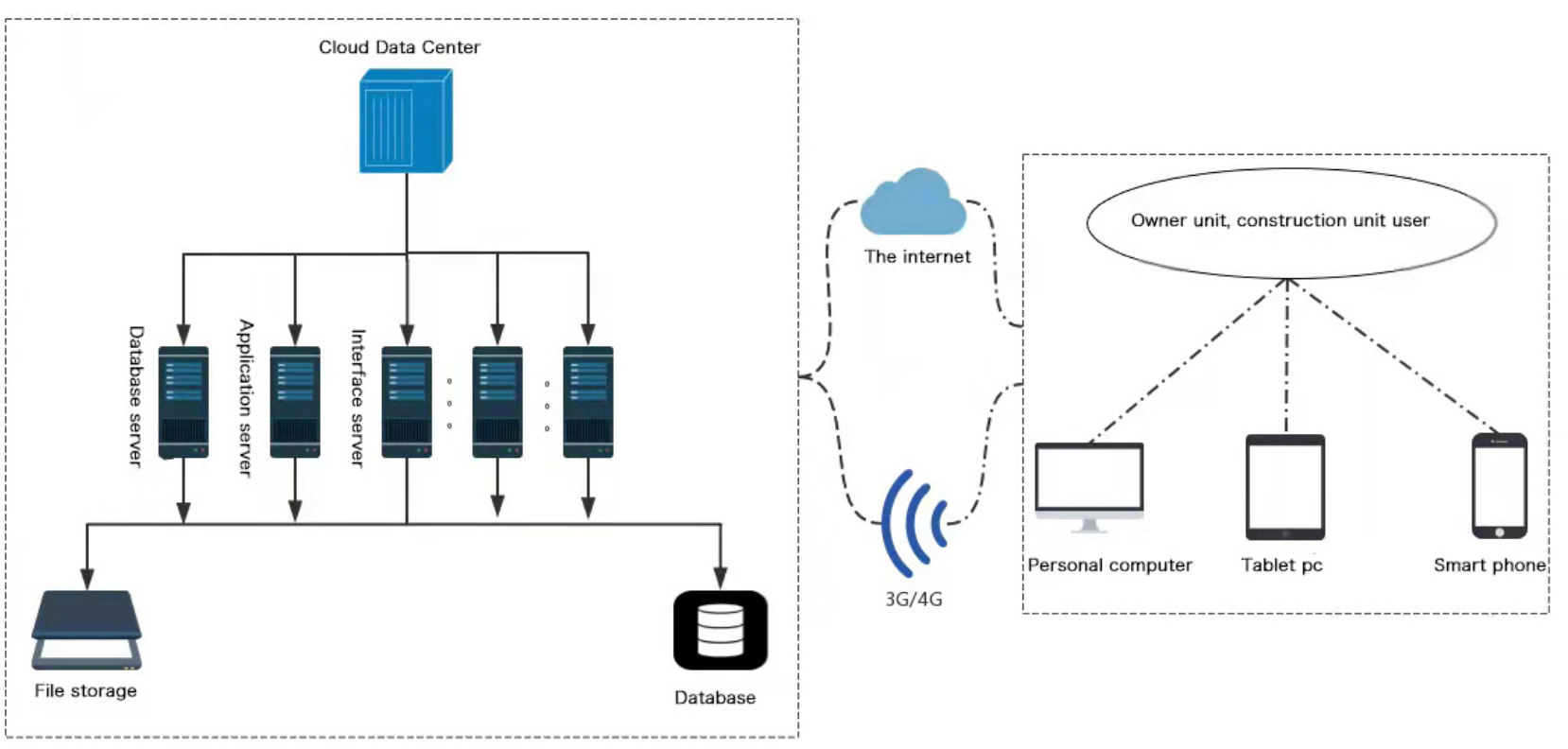

Figure 5. Application of BIM + GIS in physical structure design of highway maintenance management.

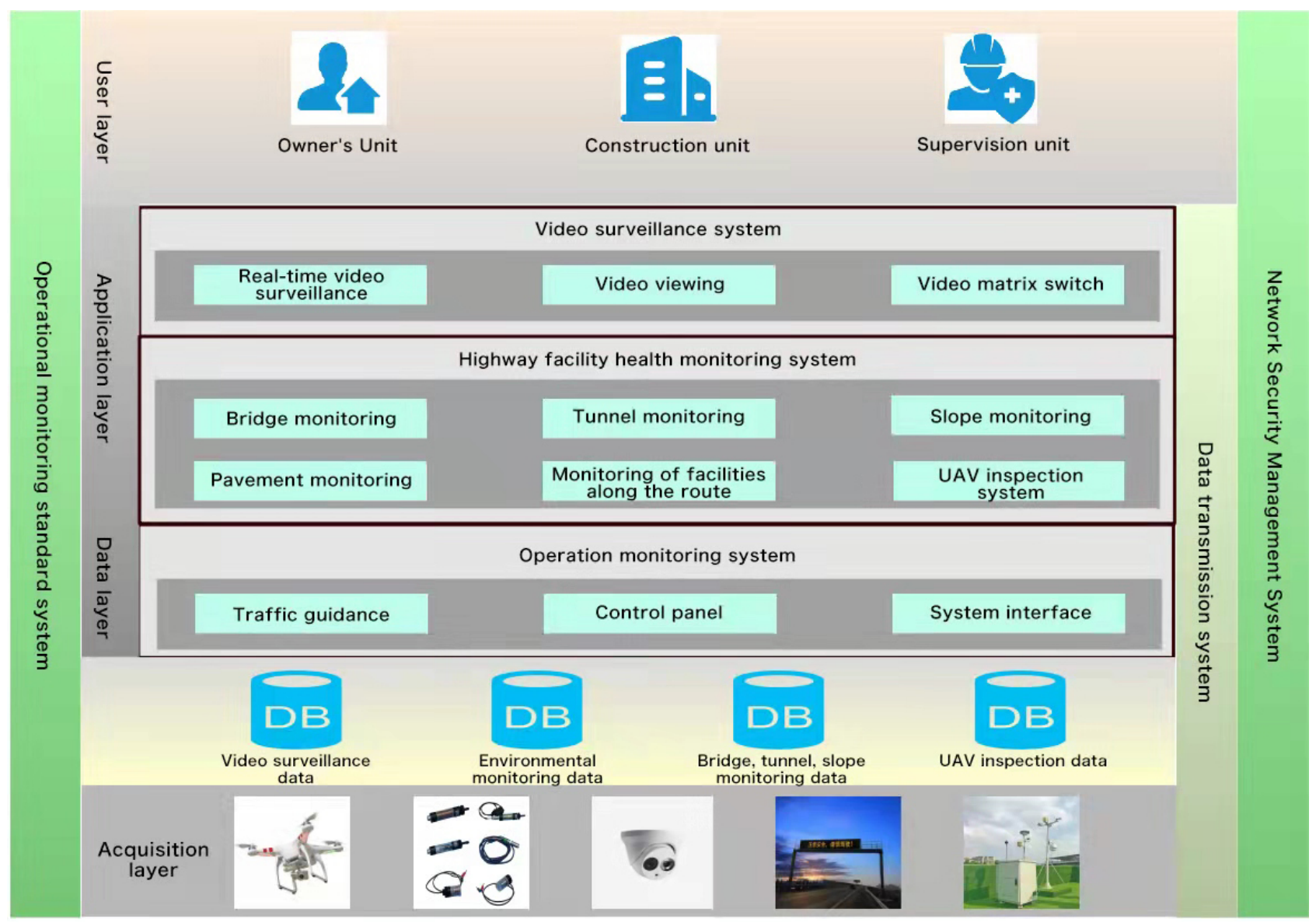

Figure 6. Logical structure design of BIM + GIS applied to highway operation and management.

The physical architecture design of the operation management platform is shown in Figure 7 below. 


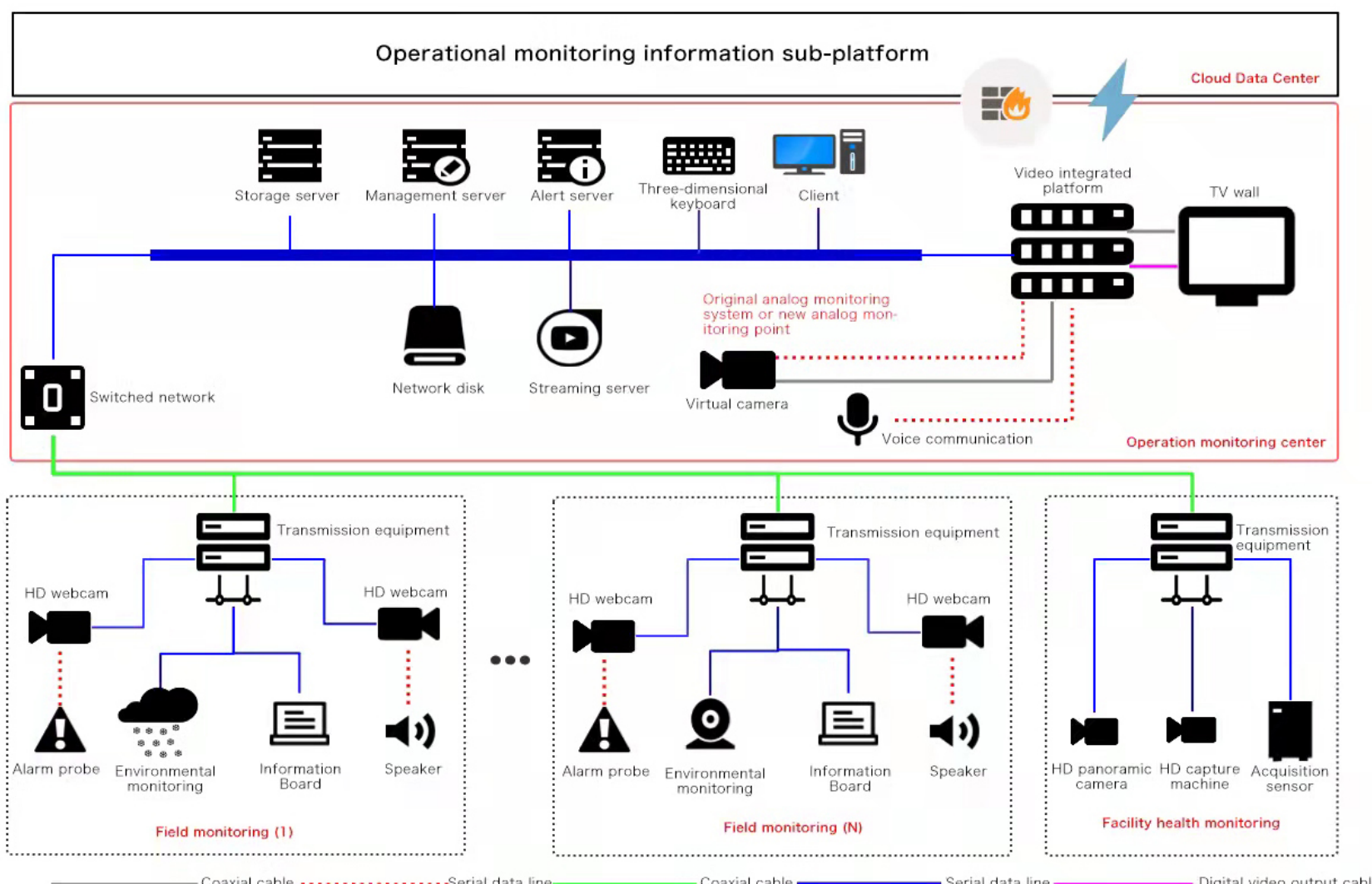

Figure 7. Physical structure design of BIM + GIS applied to highway operation management.

The overall architecture of the operation management sub platform integrates the whole highway video monitoring system and highway facility health monitoring system, realizes various business functions on the unified network architecture and comprehensive application sharing platform, realizes the integration with video images, reflects the integrity of the highway co mprehensive monitoring system and improves the sharing degree of the system.

\subsection{GIS + BIM Bottom Platform}

The logical architecture design of GIS + BIM underlying platform is shown in Figure 8 below.

The physical architecture design of GIS + BIM underlying platform is shown in Figure 9 below.

\section{BIM + GIS Technology to Solve the Path of Highway Maintenance in Gansu Province}

\subsection{Comparison of Old and New Systems}

Facing the above problems, the traditional management methods are difficult to be scientific, effective and centralized. New technical means need to be adopted to improve the management level and meet the needs of engineering construction. 


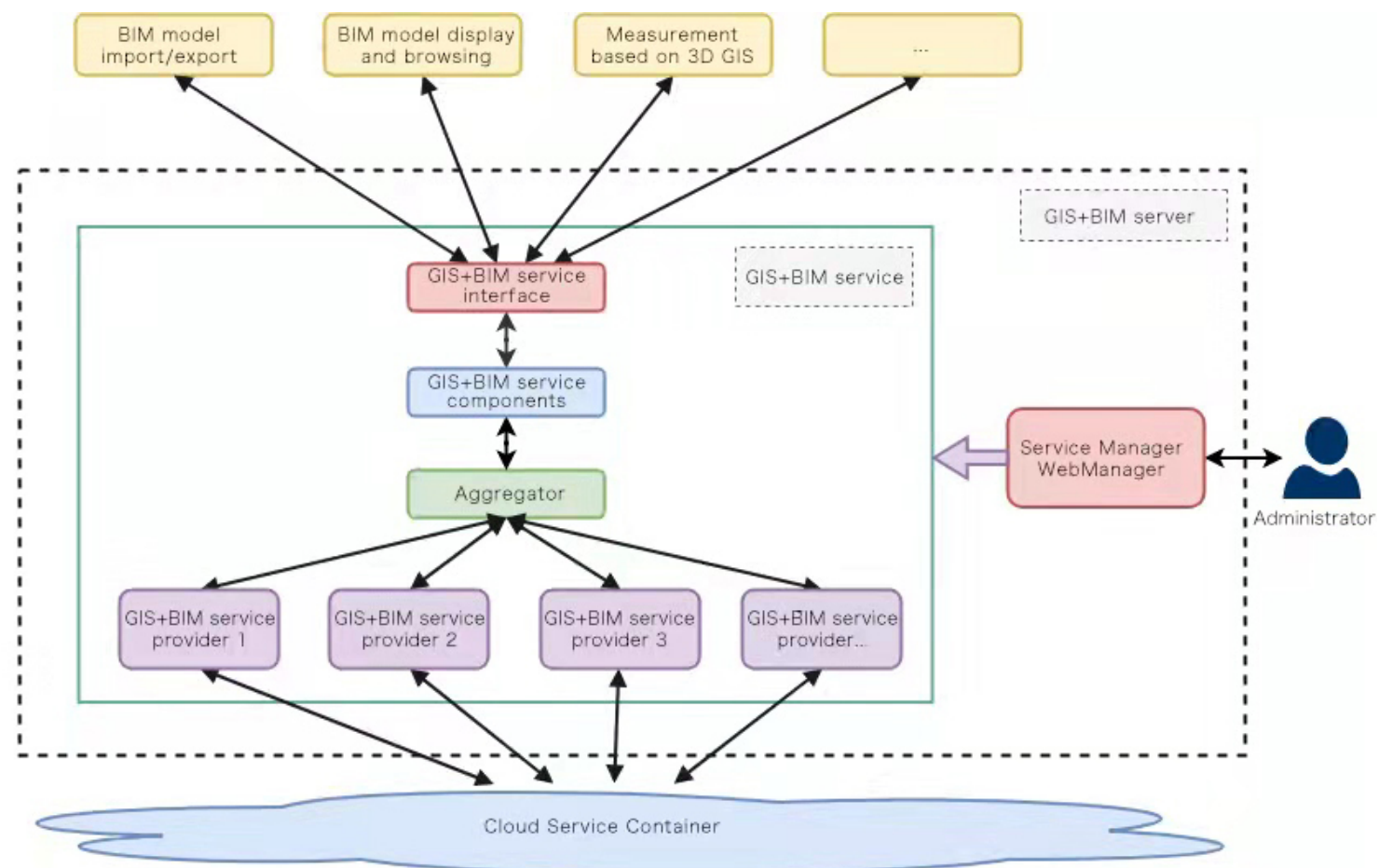

Figure 8. Logical structure design of BIM + GIS applied to highway bottom platform.

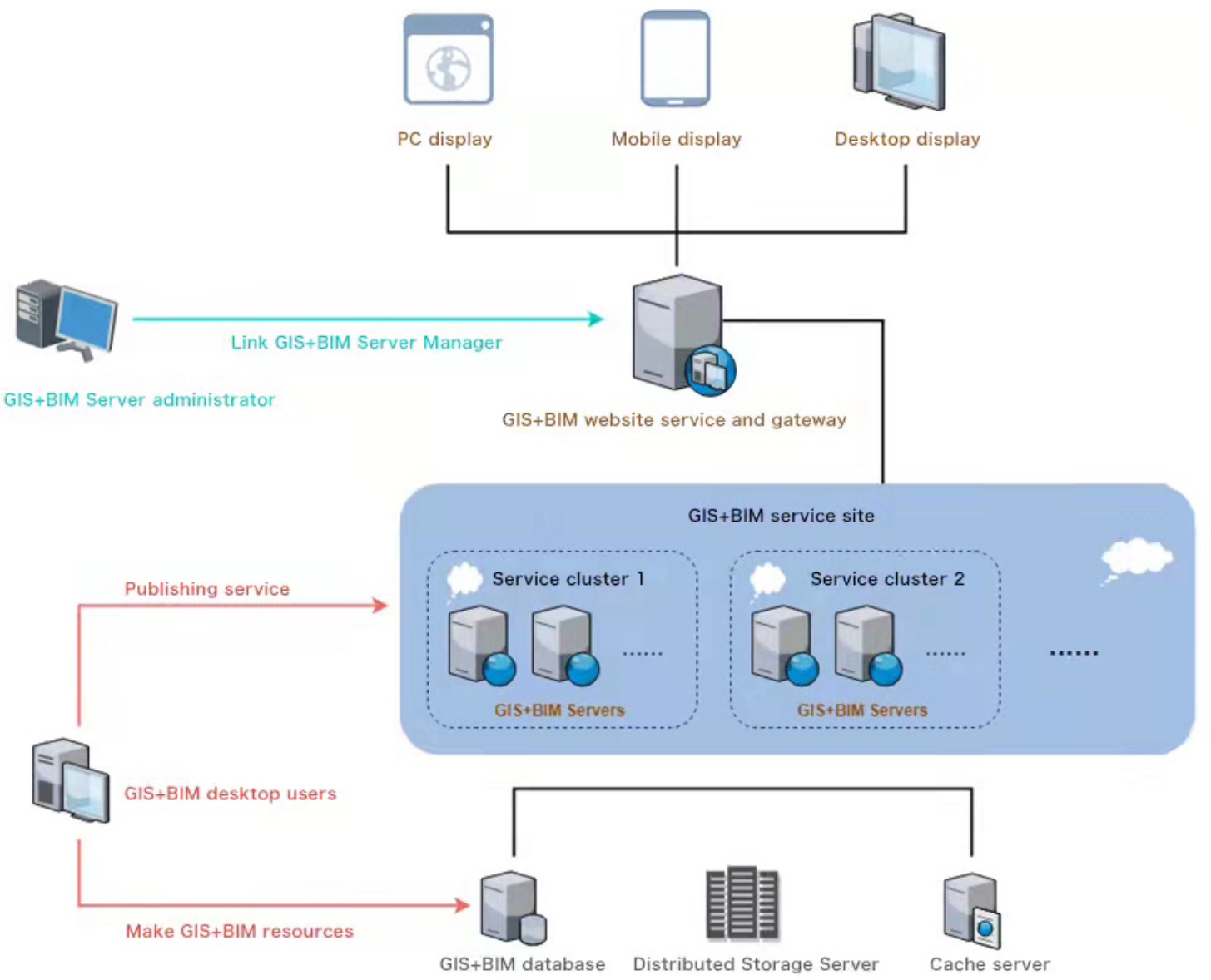

Figure 9. BIM + GIS applied to the physical structure design of highway bottom platform. 


\subsection{Application of BIM + GIS Platform}

Applying BIM + GLS technology to Gansu highway maintenance project can improve the project management level and change the traditional working mode. Use BIM + big data, cloud computing and intelligent IOT equipment to strengthen project supervision, ensure project quality and provide practical basis for the application of smart highway and digital highway. Its main operation framework is shown in Figure 10 below. The comparison between new and old systems is shown in Table 1.

Table 1. Comparison between old and new systems.

\begin{tabular}{ll}
\hline Old system & $\begin{array}{l}\text { Various systems are constructed by different stages and different implementation } \\
\text { subjects. The system is self closed, with scattered applications, information and } \\
\text { resources. It is lack } \\
\text { of collaborative management and cannot carry out effective decision support. }\end{array}$ \\
Functional & $\begin{array}{l}\text { 1. Project management requirements during construction period. } \\
\text { requirement }\end{array}$ \\
2. Project management requirements during transportation and nutrition care. \\
3. Digital management requirements of the whole process, role and business.
\end{tabular}

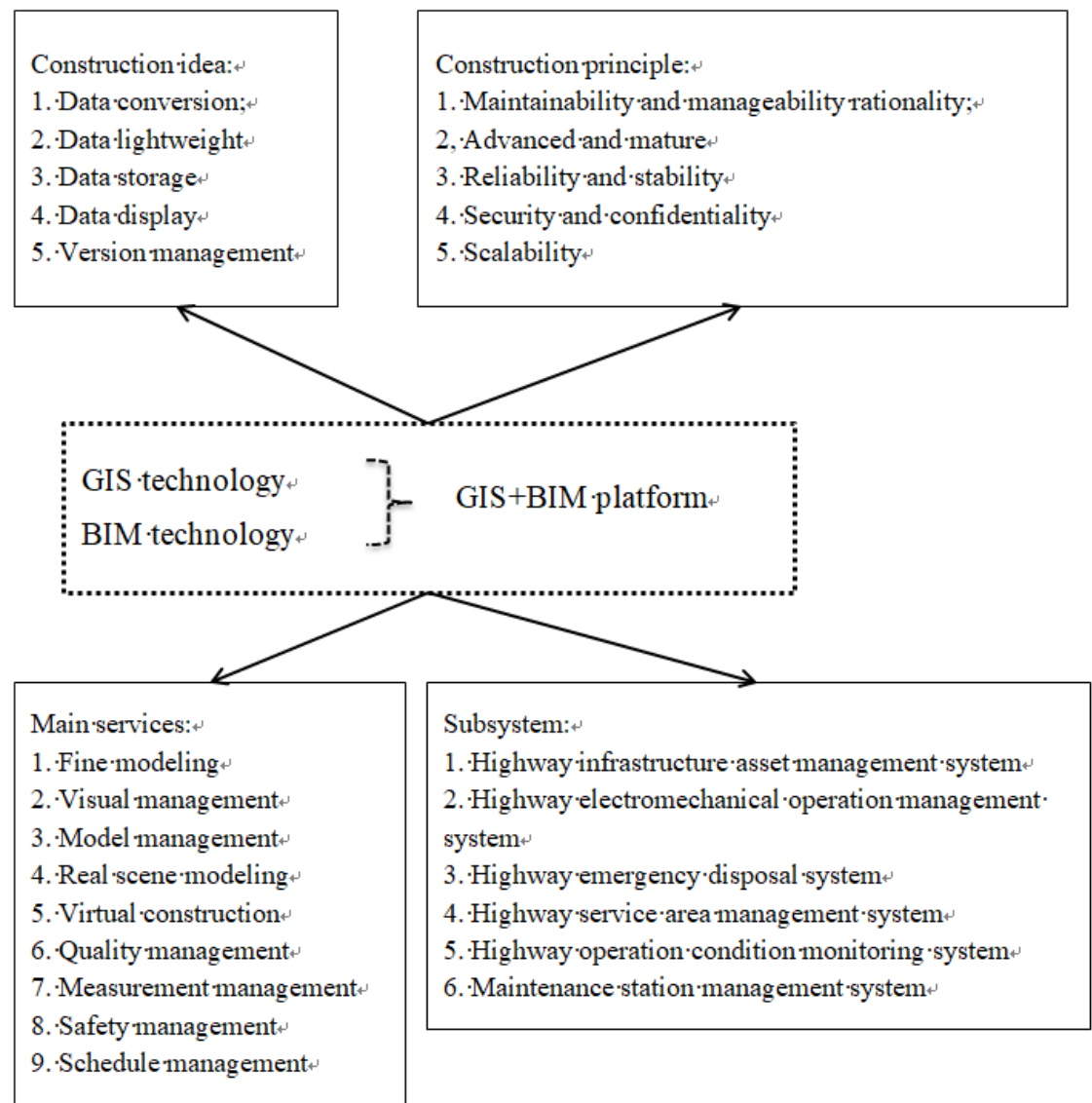

Figure 10. Operation framework of BIM + GIS applied to highway maintenance in Gansu The solutions to the key technical problems involved are as follows. 
1) Technical problems-accuracy of BIM model

BIM faces great challenges in data accuracy and needs to find a suitable solution to combine data with multiple precision or file types. Carry out in-depth integration and interactive utilization of data from the data and system level, so as to achieve the purpose of integrated application and improve data accuracy and use efficiency. Support the vertex by vertex coordinate conversion capability of 3D model, the conversion between BIM model and GIS data in plane coordinate system and geographic coordinate system, realize the accurate matching of BIM model and GIS data under the influence of earth curvature, avoid cracks and loopholes in rendering, and meet the accuracy requirements of data in the process of construction, operation, maintenance and management.

2) Technical issues massive data management

BIM contains internal structure and a large amount of data, which puts forward higher requirements for the performance of GIS software. BIM modeling software manages a single building, but GIS needs to manage the BIM data of a region or even the whole city, which requires higher performance. A large amount of data will bring huge load. If BIM data is not optimized, there will be serious performance problems in the loading and display of BIM data in GIS, affecting the user experience and application effect. Make full use of the acceleration ability of graphics hardware, store and draw the shared parts by instantiation, and pre generate 3D slice data to reduce rendering batches [11]. Displaying data with different levels of detail according to the distance from the viewpoint can greatly shorten the data loading time and improve the user experience. Design slicing and spatial index of BIM data, load data on demand, and improve data loading and rendering performance.

3) Technical problems-three-dimensional space analysis

In addition to rendering and visualization, the combination of BIM and GIS is more important to deeply integrate with the business system. To realize the association and integration of BIM data model and attribute data, BIM components are stored and managed in spatial database in an object-oriented way, and can support query, statistics and analysis. BIM data can be divided into two parts. One part is model data such as 3D model, spatial location and appearance shape, and the other part is attribute data such as associated documents and maintenance information. The two parts of data can be stored in the spatial database, so that it is convenient to view the attributes, filter query and view by category of model objects, It can realize query, statistical analysis with complex business logic.

\section{Expected Effect of BIM + GIS Technology in Highway Maintenance in Gansu Province}

\subsection{Case Presentation: Application Verification of BIM + GIS Technology in Highway Maintenance in Gansu}

1) GIS map

Effect: display project location information, relationship between line trend information and existing roads, bid section location, key projects, stations and 
stations, etc.

Value: use GIS map to master the surrounding environment of the project, the construction scope of each participant and the setting of stations.

2) BIM function level application

Scenario: virtual reality combined with management.

Effect: BIM model carries out progress coloring to realize the display of the overall progress of the project. Through the monitoring video, the specific construction situation of the project site can be viewed in real time. Combined with the panoramic function, the completion of the project can be viewed from different angles and different dates to form a panoramic image record of the construction process.

Value: through the combination of BIM model coloring, panoramic photos and video monitoring, the construction progress management and monitoring are carried out in an all-round way from virtual model, 720 degree real scene and real-time monitoring images, so that the project managers can have a more comprehensive understanding of the progress of the project site.

a) Based on GIS map and BIM model, the whole project is displayed from macro to micro, and BIM model components are used as information carriers to integrate business data such as progress, safety, quality and cost, so as to solve the problems of "information island" and "application island" between business elements in project management, and expand model application on the basis of three-dimensional display. At the same time, it provides the basis and support for data inheritance among construction, management and maintenance links [12].

Basic information: view the basic attribute information of $3 \mathrm{D}$ components based on 3D models; Design file: View 2D drawing information of 3D construction;

Progress information: view the progress information of $3 \mathrm{D}$ components based on 3D model;

Quality acceptance: Based on the 3D model, view the quality acceptance list and specific forms of 3D components, and view the specific process; GIS map and BIM function level and component level applications are shown in Figure 11;

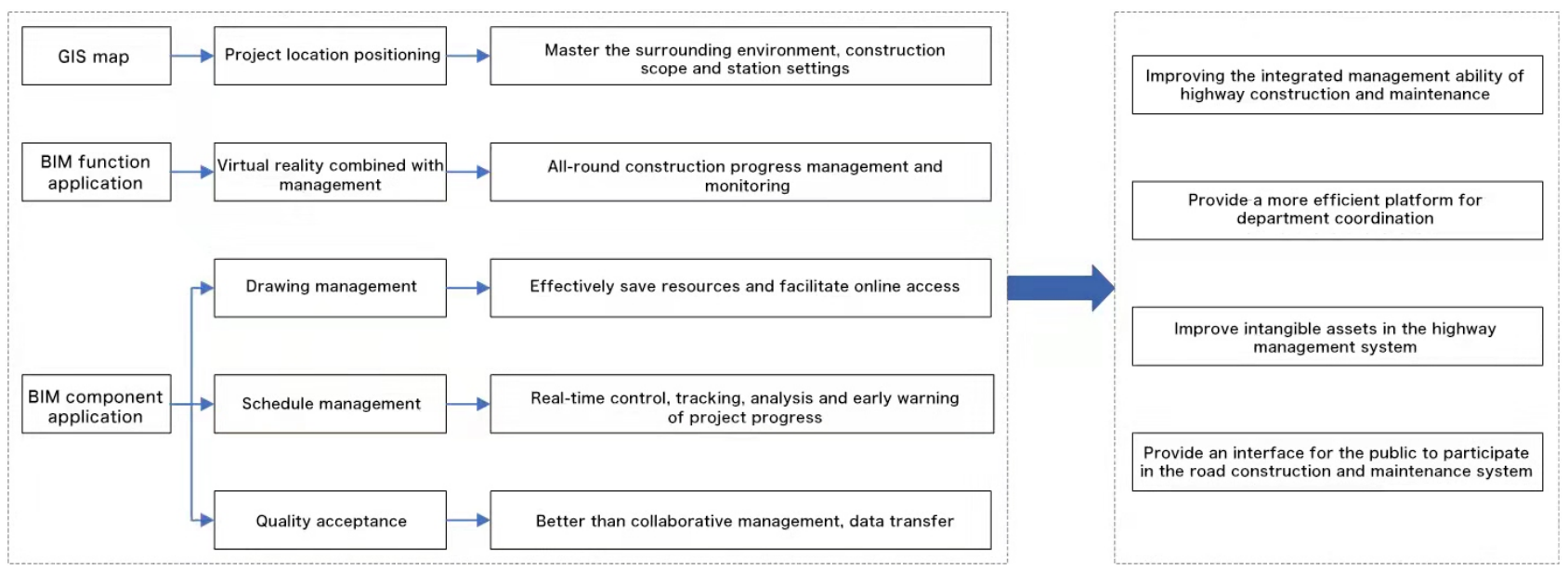

Figure 11. GIS map and BIM function level and component level application 3) BIM component level application. 
Quality problems: view the quality problems of 3D components based on 3D models;

Potential safety hazards: view the potential safety hazards related to three-dimensional components based on the three-dimensional model;

Measurement information: Based on the 3D model, view the measurement information and forms of 3D components. b.)Scenarios: Sheet management

Effect: decompose the construction drawings of the project, associate the project parts with BIM components, and view the construction drawings of corresponding parts separately in BIM components.

Value: cloud storage of project construction drawings can reduce drawing handling and storage and paper consumption, effectively save resources, and facilitate all parties of the project to consult construction drawing information online at any time according to BIM components.

b) Scenario: Schedule Management

Effect: it realizes the preparation of component level schedule, including the overall project schedule and annual, quarterly, monthly and other phased schedules. Through PC and mobile terminals, it supports the input of component progress information from multiple dimensions such as output value amount, engineering quantity percentage and image progress, and the statistical analysis of progress data from multiple dimensions such as image, output value and time.

Value: the visual characteristics of BIM are used to visually display the image progress of the project, conduct construction dynamic simulation and progress comparison according to the planned time and actual time, facilitate progress tracking and deviation analysis, and control, track, analyze and warn the progress in real time.

c) Scenario: Quality acceptance

Effect: BIM application and quality management module data exchange, the process management and quality assessment of on-site construction are associated with components, and the quality management data is loaded automatically in real time. By clicking the model component, you can directly view the component process acceptance status and relevant quality inspection forms, and the component process acceptance status can be colored for three-dimensional visual display.

Value: associating the quality information with the BIM model makes the transmission of quality information faster. Through the BIM model, all project participants can more easily view the process acceptance data information and process acceptance process of the project parts under their jurisdiction, which can give full play to the advantages of collaborative management, and transfer real, detailed and timely data to facilitate work.

\subsection{Case Presentation: Application Effect of BIM + GIS Technology in Rural Highway Maintenance in Gansu Province}

1) Improve the integrated management ability of highway construction and maintenance

The highway construction and maintenance integration platform adopts new 
generation information technologies such as big data analysis, GIS, cloud computing, Internet of things, BIM, AI, VR and AR to realize the full circulation of business data in the whole life cycle of construction, maintenance and operation, ensure the real-time communication of information between all parties involved in the construction stage, maintenance stage and operation stage, avoid information island, and realize construction, maintenance Collaborative management at all stages of operation.

2) Provide a more efficient platform for department coordination

The integrated platform for construction, management and maintenance of highway engineering has established a real-time, stable and unified information-based collaborative working environment for the government, all units in the construction stage, all units in the maintenance stage and all units in the operation stage, which enables relevant departments of highway engineering to highly share information, work together efficiently, coordinate and process business on a unified platform Form a scientific system of knowledge accumulation and jointly face the changes of social environment, so as to effectively meet the needs of social development.

3) Improve the intangible assets in the highway management system

The construction of the integrated platform of highway construction, management and maintenance will accumulate valuable intangible assets and information wealth such as data, data and management experience for highway construction and management, realize the value-added efficiency of highway assets, and provide reference and support for highway construction and management in the future.

4) Provide interface for public participation in highway construction and maintenance system

In addition to providing information means and support for management and decision-making, the integrated management platform of construction, management and maintenance will also become a powerful tool and information source for the majority of highway users. After the completion of the integrated management platform of construction, management and maintenance, the functions of geographic information query, road condition query, real-time road condition monitoring image and simulated driving will be opened to the public, so as to provide the public with modern intelligent services such as real-time navigation, speed reminder and emergency rescue.

\section{Project Name and Number}

This research funded by Fund Project: Gansu transportation science and technology project 2020-11, national key R \&amp, D plan 2019YFB1600703.

\section{Conflicts of Interest}

The authors declare no conflicts of interest regarding the publication of this paper. 


\section{References}

[1] Tian, Q., Zhou, J., Rui, Y.Q., et al. (2009) Research on Information Construction of Huaishuping Tunnel Based on BIM + GIS. Zhongwai Highway, 39, 250, 167-170.

[2] Min, S.P. and Zhao, L.L. (2014) Application of 3D GIS Technology in Railway Life Cycle. Journal of Railway Engineering, 31, 15-20.

[3] Bao, L., Yang, B., Yang, W., et al. (2021) Research and Application of Key Technologies of One Map of Railway Engineering Construction Management Based on BIM + GIS. Railway Standard Design, 65, 6.

[4] Jiang, Y.L., Xia, Y.J. and He, B. (2020) Application of BIM Lightweight Technology Based on GIS in Bridge Engineering. Highway, 65, 123-127.

[5] Bian, X.C., Lei, C., Ding, G.J., et al. (2018) Research and Development of Hydropower Project Group Construction Management System Based on GIS + BIM. People's Yangtze River, 49, 76-80.

[6] Lin, X.D., Li, X.J. and Lin, H. (2018) AGIS/BIM Integrated Lifecycle Management System for Shield Tunnel. Tunnel Construction, 38, 963-970.

[7] Ma, Z. and Ren, Y. (2017) Integrated Application of BIM and GIS: An Overview. Procedia Engineering, 196, 1072-1079.

[8] Wang, C., Xia, J.P., Xu, R., et al. (2019) Research on Tunnel Information Construction Technology Based on BIM + GIS. People's Yellow River, S2, 114-116+127.

[9] Che, D.K. (2021) Application of GIS + BIM Technology in the Construction of a Characteristic Town. Chinese Building Metal Structure, No. 3, 4.

[10] Wang, X.J. (2018) Integrated Application of GIS and BIM Technology in Beiheng Channel Project. The 4th National BIM Academic Conference, Hefei, November 2018, 24-25.

[11] Xiong, G.K., Zhu, L.L. and Xue, M. (2017) Application of Gis-BIM Technology in Road Network Optimization Design of Mountainous Cities. Journal of Chongqing Jiaotong University (NATURAL SCIENCE EDITION), 36, 90-95.

[12] Liu, G. (2008) Information-Based and Safety of Highways Should Start with Sign Facilities-Analysis of the Setting and Management of Sign Facilities of Highways. Traffic Construction and Management, No. 4, 46-47. 